\title{
Pharmacological targeting of the constitutively activated MEK/MAPK-dependent signaling pathway in glioma cells inhibits cell proliferation and migration
}

\author{
ALEXANDER GLASSMANN ${ }^{1,4}$, KARL REICHMANN $^{3}$, BJÖRN SCHEFFLER ${ }^{2}$, \\ MARTIN GLAS $^{2}$, NADINE VEIT ${ }^{3}$ and RAINER PROBSTMEIER ${ }^{3}$ \\ ${ }^{1}$ Department of Anatomy, Anatomy and Cell Biology, University of Bonn; ${ }^{2}$ Institute of Reconstructive Neurobiology; \\ ${ }^{3}$ Neuro- and Tumor Cell Biology Group, Department of Nuclear Medicine, University of Bonn Medical Center, Bonn, Germany
}

Received May 18, 2011; Accepted July 1, 2011

DOI: $10.3892 /$ ijo.2011.1165

\begin{abstract}
Activated mitogen-activated protein kinase MAPK cascade leading to ERK1/2 phosphorylation is expressed in the majority of glial neoplasms and negatively correlates with survival time of patients. Here we show that ERK1/2 kinases are constitutively activated in glioma cell lines and stem cellenriched primary cultures of glioblastoma. Pharmacological targeting of the activated MEK/ERK1/2 module with the MEK inhibitor U0126 attenuates cell cycle progression (11 out of 11 cell lines), impairs single ( 7 out of 10) and collective cell migration (9 out of 11) and abolishes single cell emigration from monolayers (4 out of 9). Attacking the activated MEK/ ERK1/2 module thus partially blocks the tumorigenic potential of glial cancer cells on different levels and strongly suggests the application of combination molecularly targeted therapies to interfere more efficiently with glial tumor development and progression.
\end{abstract}

\section{Introduction}

Amongst the different signal transduction pathways, the mitogen-activated protein kinase (MAPK) pathway plays a fundamental role in that it brings together a number of different extracellular signals influencing a variety of phenomena involved in cellular behavior such as proliferation, migration, differentiation or survival (1). This pathway is characterized

Correspondence to: Dr Rainer Probstmeier, Neuro- and Tumor Cell Biology Group, Department of Nuclear Medicine, University of Bonn, Sigmund-Freud-Str. 25, D-53105 Bonn, Germany

E-mail: r.probstmeier@uni-bonn.de

Present address: ${ }^{4}$ Life Science Inkubator, Bonn, Germany

Key words: extracellular signal-regulated kinases 1/2, glioma, invasion, mitogen-activated protein kinase, MEK, migration, proliferation, U0126 by the activation of Ras GTPase, leading to an activation of the serine/threonine kinase Raf which in turn phosphorylates MEK (MAP/ERK kinase), the latter activating extracellular signal-regulated kinases (ERKs) $(1,2)$. In cancer research the MAPK cascade leading to ERK1/2 activation has been subject of particular interest as this pathway is activated in a broad spectrum of tumors and may thus represent a potential molecular target for therapeutic intervention (2). The cellular outcome of ERK1/2 signaling is complex, because signal specificity can be modified by the duration, magnitude and subcellular localization of ERK activation, thereby even leading to opposite effects, i.e. cell proliferation versus cell cycle arrest and cell differentiation (3).

Constitutively activated ERK $1 / 2$ is expressed in many human cancers derived from different organs, such as brain, colon, kidney, lung or cells of hematopoietic origin $(4,5)$. The presence of activated ERK1/2 has been also documented in glial neoplasms (6-8), whereby activated ERK1/2 correlates with decreased overall survival time of patients and increased tumor resistance to radiotherapy $(8,9)$. Gliomas are the most frequent central nervous system tumors that arise from astrocytes, oligodendrocytes or their respective precursors (10). Although mutational activation of Ras proteins is absent in high-grade gliomas, an increased Ras activity is present in these tumors, most likely due to overexpression and constitutive activity of upstream signaling elements or downregulation of Ras repressor proteins (11).

A number of pharmacological agents interfere with the Ras/Raf/MEK/ERK signaling cascade including U0126 that inhibits MEK in a non-substrate competitive manner (12). U0126 is supposed to directly inhibit the catalytic activity of MEK but, in contrast to PD98059, does not block its phosphorylation by Raf (12).

Here we show that ERK1/2 is constitutively activated, i.e. phosphorylated (pERK1/2), in established glioma cell lines as well as in primary tumor (stem) cells in a MEK-dependent, i.e. U0126-inhibitable manner. In glioma cell lines, pharmacological targeting of the MEK/ERK1/2 module only partially inhibits cell proliferation and migration, suggesting an inclusion of comparable small molecule kinase inhibitors only in the frame of combination therapies. 
A

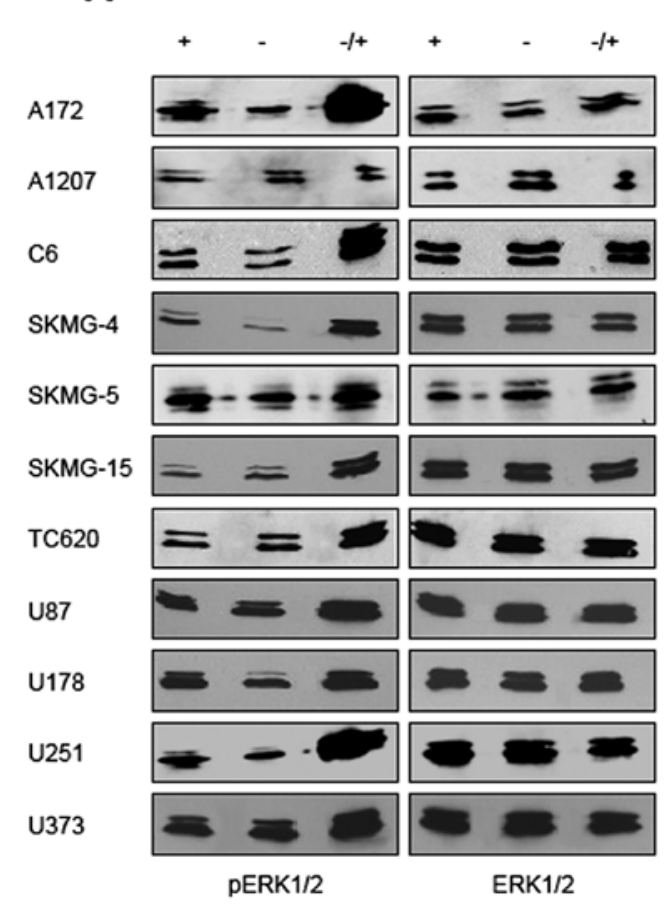

B

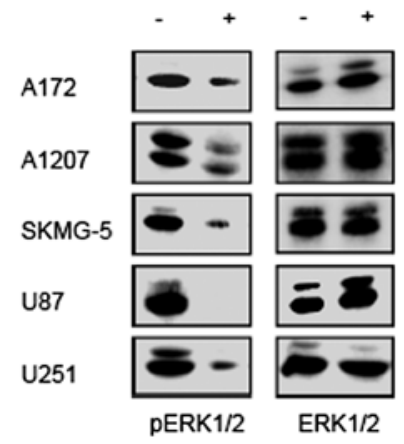

Figure 1. Western blot analysis of ERK1/2 activation in glioma cells. (A) Glioma cells were cultured for $24 \mathrm{~h}$ in DMEM, 10\% FCS (+), DMEM (-) and DMEM, $+10 \%$ FCS (during the final 20 min of culture; -/+). (B) Glioma cells were cultured for $24 \mathrm{~h} \pm 10 \mu \mathrm{M}$ U0126. Cell lysates were analyzed for the presence of total or phosphorylated (p)ERK1/2 proteins using specific antibodies.

\section{Materials and methods}

Materials. The following materials were used: MEK inhibitor U0126 (Promega), phalloidin-TRITC (Sigma), monoclonal phospho-p44/42 MAPK antibody to dually phosphorylated ERK1/2, and polyclonal p44/42 MAPK antibodies recognizing both phosphorylated and unphosphorylated ERK1/2 (Cell Signaling Technology/New England Biolabs).

Cell lines and culture conditions. Human glioma cell lines A172, A1207, U87MG, U178MG, U251MG, U373MG, SK-MG4, SK-MG5, SK-MG15, human oligodendroglioma cell line TC620 and rat glioma cell line C6 were cultured in Dulbecco's modified Eagle's medium (DMEM) containing $10 \%$ fetal calf serum (FCS) as described (13). In inhibition experiments, the MAPK kinase inhibitor U0126 (1 mg/ml in DMSO; final concentration $10 \mu \mathrm{M}$ ) or the respective amount of the solvent was added. In long-term experiments, fresh inhibitor was added every second day. Primary cultures of human glioblastoma cells were derived from the center regions of resected tumor tissue and maintained in defined, serum free, stem cell-favorable conditions as previously described (14).

Cell extraction and Western blot analysis. Cell solubilization in the presence of protease and phosphatase inhibitors $(1 \mathrm{mM}$ Na-orthovanadate, $1 \mathrm{mM}$ phenylmethylsulfonyl fluoride, $2 \mu \mathrm{M}$ soybean trypsin inhibitor) and Western blot analyses were carried out as described (13).

Cell proliferation assay. Four hundred cells in $100 \mu \mathrm{l}$ culture medium were seeded in 96 -well plates (12 wells per time point and treatment). Twenty-four hours later (T0), cells were either fixed with 4\% formaldehyde in PBS, or U0126 (final concentration $10 \mu \mathrm{M}$ ) or respectively DMSO (solvent for U0126) was added in $100 \mu \mathrm{l}$ of culture medium. At this concentration, U0126 affects only the activity of MEK without a considerable impact on other kinases. After a further culture period of $72 \mathrm{~h}$ (T1) cells were also fixed with $4 \%$ formaldehyde. Cells from both time points were then stained with DAPI $(1 \mu \mathrm{g} / \mathrm{ml}$ in PBS) and the cell number in a defined area of each well was determined microscopically.

Collective cell migration assay. Nine thousand cells in a total volume of $3 \mu \mathrm{l}$ were spotted onto Petri dishes and allowed to adhere overnight. After floating the dishes with culture medium, the adherent and confluent cells occupied a circular area. Diameters of areas (12 per dish) were determined microscopically subsequently after floating (T0) and a second time after a 72-h culture period (T1) with or without $10 \mu \mathrm{M}$ U0126.

Single cell migration assay. Four thousand cells in $500 \mu 1$ culture medium were applied to 24 -well plates and allowed to adhere overnight. Six hours prior to time-lapse analysis, U0126 (final concentration $10 \mu \mathrm{M}$ ) or DMSO (both diluted in $500 \mu \mathrm{l}$ culture medium) was added per well. Time-lapse microscopy and analysis was performed as described (29). Briefly, plates were transferred to a heated $\left(37^{\circ} \mathrm{C}\right)$, gassed $\left(5 \% \mathrm{CO}_{2} /\right.$ air $)$ and humidified chamber fitted onto an inverted microscope (Leica DM IRE2 HC Fluo) with a motorized cross-stage. Images were recorded every $10 \mathrm{~min}$ for $24 \mathrm{~h}$. Cell movement was tracked and analyzed with ImageJ plugin MTrackJ (www. imagescience.org/meijering/software/mtrackj/). 

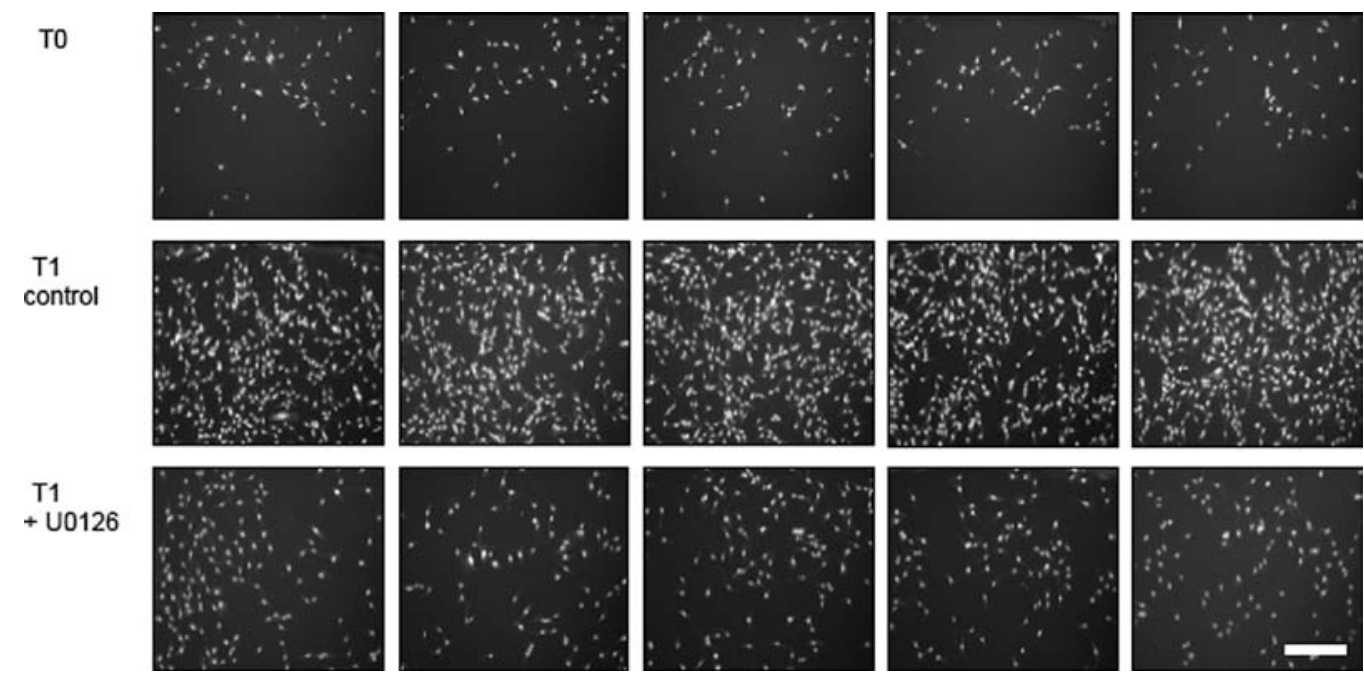

Figure 2. MEK/ERK1/2-dependent proliferation of glioma cells. Low-density U87 cells were cultured in 96-well plates for 0 (T0) or $72 \mathrm{~h}$ (T1) $\pm 10 \mu \mathrm{M}$ U0126, fixed with $4 \%$ formaldehyde and finally stained with DAPI. Representative micrographs of comparable areas in five different wells are shown for each timepoint and treatment. Bar, $200 \mu \mathrm{m}$.

Table I. Impact of U0126 treatment on glioma cell proliferation.

\begin{tabular}{|c|c|c|c|c|c|}
\hline Cell line & $\begin{array}{l}\text { Doubling time (h) } \\
\text { - control - }\end{array}$ & $\begin{array}{l}\text { Doubling time (h) } \\
\text { - U0126 - }\end{array}$ & $\begin{array}{l}\text { Fold increase } \\
\text { doubling time }\end{array}$ & $\%$ inhibition $^{\mathrm{a}}$ & p-value \\
\hline A172 & $17.6 \pm 2.10$ & $21.7 \pm 2.50$ & 1.2 & 43 & $<0.01^{* *}$ \\
\hline A1207 & $36.5 \pm 17.7$ & $63.5 \pm 16.2$ & 1.8 & 45 & $<0.001^{* * * *}$ \\
\hline C6 & $23.4 \pm 3.20$ & $39.3 \pm 3.20$ & 1.7 & 59 & $<0.001^{* * * *}$ \\
\hline SKMG-4 & $20.5 \pm 3.50$ & $34.0 \pm 8.50$ & 1.6 & 62 & $<0.01^{* *}$ \\
\hline SKMG-5 & $39.7 \pm 9.70$ & $51.2 \pm 10.1$ & 1.3 & 26 & $<0.05^{*}$ \\
\hline SKMG-15 & $19.0 \pm 2.80$ & $28.0 \pm 1.40$ & 1.2 & 57 & $<0.01^{* *}$ \\
\hline TC620 & $30.0 \pm 5.40$ & $42.5 \pm 8.50$ & 1.4 & 38 & $<0.001^{* * *}$ \\
\hline U87 & $25.3 \pm 4.10$ & $42.3 \pm 8.70$ & 1.7 & 55 & $<0.001^{* * *}$ \\
\hline U178 & $25.0 \pm 1.50$ & $47.0 \pm 8.90$ & 1.9 & 62 & $<0.01^{* *}$ \\
\hline $\mathrm{U} 251$ & $35.2 \pm 12.0$ & $65.0 \pm 13.1$ & 1.8 & 50 & $<0.001^{* * *}$ \\
\hline U373 & $32.1 \pm 7.70$ & $72.5 \pm 33.4$ & 2.3 & 79 & $<0.001^{* * *}$ \\
\hline
\end{tabular}

Cells were seeded at low density in 96-well plates and cultured for $72 \mathrm{~h} \pm 10 \mu \mathrm{M}$ U0126. For counting, fixed cells were stained with DAPI at the beginning and end of the culture period and the number of cells present in a defined area determined microscopically for ten wells per time point and treatment. Doubling time was calculated from three independent experiments and mean values \pm SD are shown. Statistical significance was evaluated with an unpaired two-sample Student's t-test. ${ }^{\text {aO }}$ cell number after three days in culture. Asterisks indicate statistical significance.

\section{Results}

MEK/ERK1/2 pathway is constitutively activated in glioma cell lines. Human glioma (A172, A1207, U87MG, U178MG, U251MG, U373MG, SKMG-4, SKMG-5, SKMG-15), oligodendroglioma (TC620) and rat glioma (C6) cell lines were either cultured for $48 \mathrm{~h}$ in DMEM in the presence or absence of $10 \%$ FCS, or for $48 \mathrm{~h}$ in the absence and finally for further $20 \mathrm{~min}$ in the presence of $10 \%$ serum. In Western blot analyses, pERK1/2 was detectable in all cell lines when cultured in the absence of serum, suggesting a constitutive activation of ERK1/2 (Fig. 1A). With the exception of A1207 and SKMG-4 cells, serum stimulation of cells maintained for $48 \mathrm{~h}$ in serum-free medium led to a significant increase in pERK1/2 expression level (Fig. 1A). The expression level of pERK1/2 was drastically reduced in the presence of MEK inhibitor U0126 (Fig. 1B). U0126 was used at a concentration of $10 \mu \mathrm{M}$ throughout the study; at higher doses, appreciable cell death was evident, as determined by trypan blue staining. In contrast to glioma cells, primary astrocytes derived from early postnatal mouse brain did not express pERK1/2 (not shown).

Activated MEK/ERK1/2 promotes glioma cell proliferation. Glioma cells were seeded at low density in 96-well plates and allowed to proliferate for three days in the absence or presence of U0126 (Fig. 2, Table I). For untreated cells doubling time 


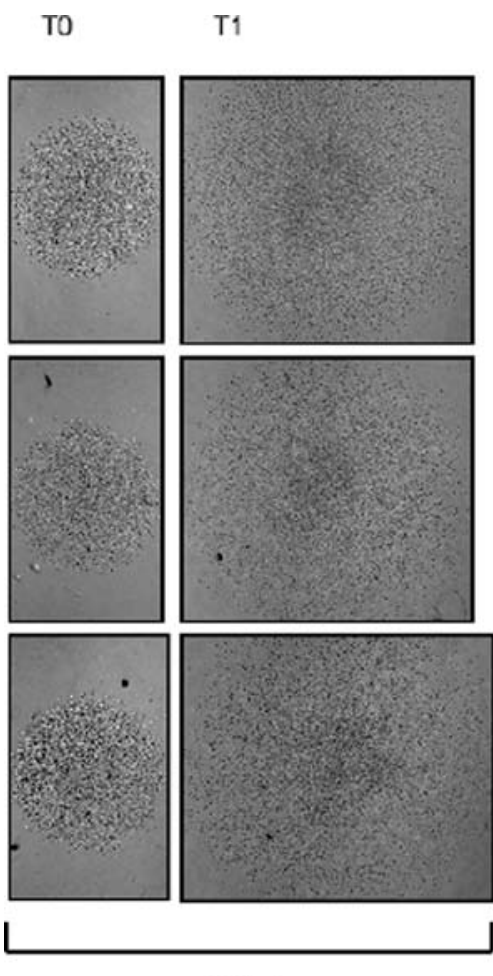

T0
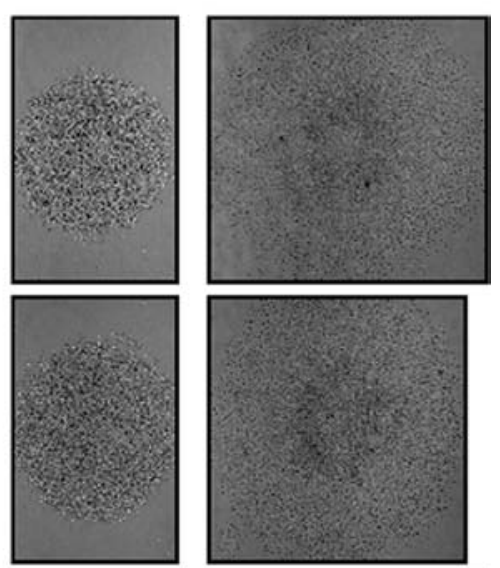

control

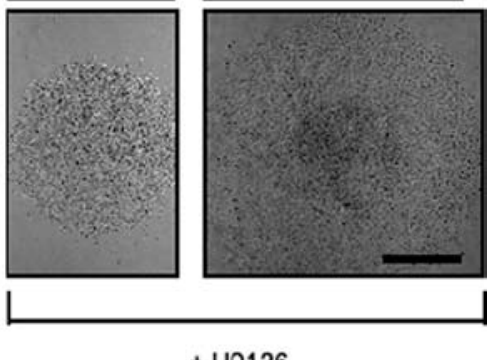

+ U0126

Figure 3. MEK/ERK1/2-dependent collective cell migration of glioma cells. U251 cells were forced to adhere as circular confluent monolayers (diameter $1-2 \mathrm{~mm}$ ) on a plastic surface and allowed to migrate for $72 \mathrm{~h} \pm 10 \mu \mathrm{M}$ U0126. Diameters of monolayers were determined before (T0) and after (T1) the 72-h culture period. Representative micrographs of three out of every twelve untreated (control) or treated (+ U0126) monolayers are shown. Bar, $0.5 \mathrm{~mm}$.

Table II. Impact of U0126 treatment on collective cell migration of glioma cells.

\begin{tabular}{|c|c|c|c|c|}
\hline Cell line & $\begin{array}{c}\text { Increase in area } \\
\left(\mathrm{mm}^{2} / \text { day } / \mathrm{mm}^{2}\right) \\
\text { - control - }\end{array}$ & $\begin{array}{c}\text { Increase in area } \\
\left(\mathrm{mm}^{2} / \text { day } / \mathrm{mm}^{2}\right) \\
\text { - U0126 - }\end{array}$ & $\%$ inhibition & p-value \\
\hline A172 & $0.98 \pm 0.04$ & $0.75 \pm 0.02$ & $26 \pm 3$ & $<0.01^{* *}$ \\
\hline A1207 & $0.84 \pm 0.10$ & $0.78 \pm 0.08$ & $18 \pm 9$ & $<0.5$ \\
\hline C6 & $0.27 \pm 0.05$ & $0.18 \pm 0.06$ & $32 \pm 14$ & $<0.01^{* *}$ \\
\hline SKMG-4 & $0.22 \pm 0.05$ & $0.17 \pm 0.03$ & $23 \pm 5$ & $<0.01^{* *}$ \\
\hline SKMG-5 & $0.32 \pm 0.01$ & $0.20 \pm 0.07$ & $36 \pm 13$ & $<0.01^{* *}$ \\
\hline SKMG-15 & $0.48 \pm 0.16$ & $0.27 \pm 0.03$ & $39 \pm 16$ & $<0.01^{* *}$ \\
\hline TC620 & $0.44 \pm 0.13$ & $0.30 \pm 0.03$ & $31 \pm 2$ & $<0.01^{* *}$ \\
\hline U87 & $0.46 \pm 0,08$ & $0.31 \pm 0.05$ & $42 \pm 17$ & $<0.001^{* * * *}$ \\
\hline U178 & $0.76 \pm 0,24$ & $0.51 \pm 0,23$ & $33 \pm 3$ & $<0.001^{* * * *}$ \\
\hline U251 & $0.58 \pm 0.08$ & $0.40 \pm 0.07$ & $31 \pm 14$ & $<0.01^{* *}$ \\
\hline U373 & $0.35 \pm 0.07$ & $0.39 \pm 0.11$ & $4.0 \pm 7$ & $<0.5$ \\
\hline
\end{tabular}

Cells at high density (9000 cells in $3 \mu \mathrm{l}$ ) were seeded onto twelve defined regions per Petri dish and allowed to adhere overnight. Dishes were then floated with culture medium (T0) and cells were treated for three days (T1) with or without $10 \mu \mathrm{M} \mathrm{U0126.} \mathrm{Diameters} \mathrm{of} \mathrm{circular} \mathrm{areas} \mathrm{occu-}$ pied by cells (Fig. 3) were determined at T0 and T1. Two to five experiments were performed for each cell line. The values shown are normalized in respect to the initial areas occupied by cells. Thus, values (given as mean \pm SD) represent increase in area per day (in $\mathrm{mm}^{2}$ ) per $\mathrm{mm}^{2}$ of the initial area at T0. Statistical significance was evaluated with an unpaired two-sample Student's t-test. Asterisks indicate statistical significance.

varied from 17.6 (A172) to $39.7 \mathrm{~h}$ (SKMG-5), with a mean value of $27 \pm 7 \mathrm{~h}$. U0126 treatment provoked a significant reduction in cell proliferation (Table I) and prolonged the doubling time by factor 1.2 (for A172 cells) up to 2.3 (for U373 cells) with a mean value of 1.6. In respect to cell number, proliferation was inhibited by 26 (SKMG-5 cells) to 79\% (U373 cells) after the 3-day culture period. Longer culture times (up to nine days) did not affect doubling time as verified for A172 and U87 cells. 

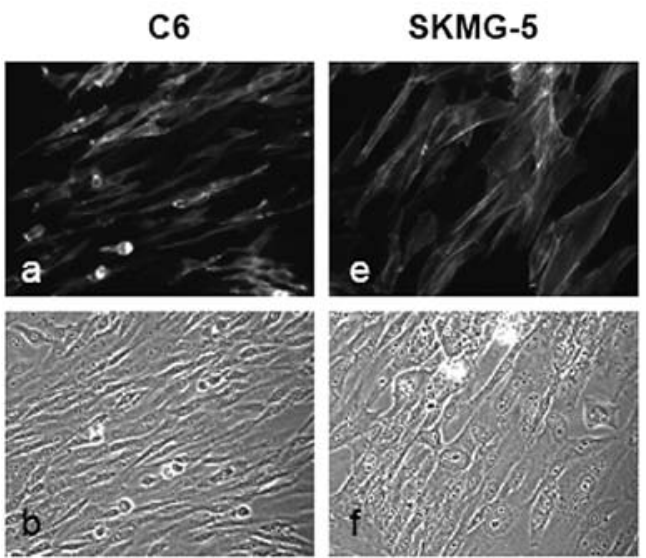

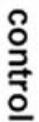
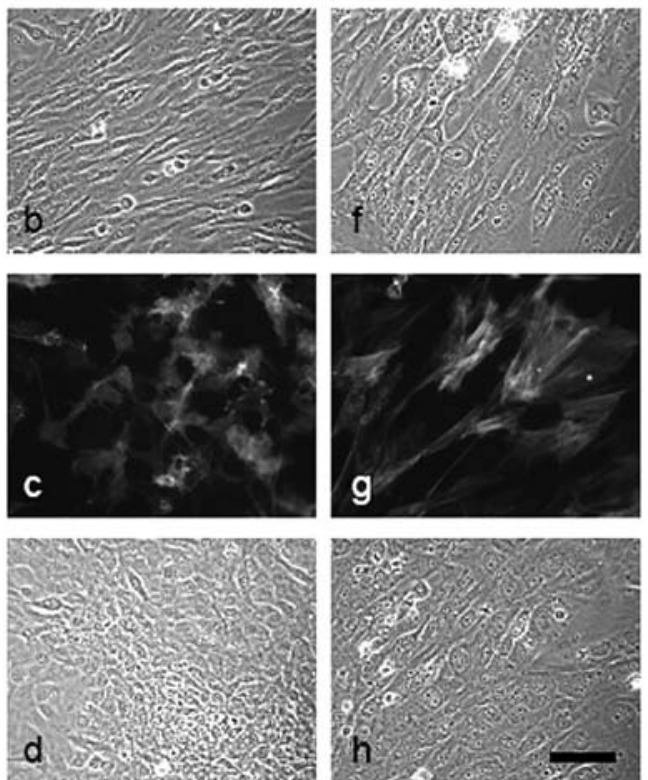

$\stackrel{+}{\stackrel{+}{\circ}}$

Figure 4. MEK/ERK1/2-dependent perturbation of the actin cytoskeleton in C6 glioma cells. Confluent monolayers of C6 (a-d) and SKMG-5 glioma cells (e-h) that had been cultured three days $\pm 10 \mu \mathrm{M}$ U0126 were labeled with phalloidin-TRITC. Phase contrast micrographs $\mathrm{b}, \mathrm{d}$ and $\mathrm{f}, \mathrm{h}$ correspond to the fluorescent images given in a, c and e, g. In d, note the roundish morphology of U0126-treated C6 cells. Bar, $50 \mu \mathrm{m}$

Table III. Impact of U0126 treatment on emigration of glioma cells from cell monolayers.

\begin{tabular}{ccc}
\hline Cell line & $\begin{array}{c}\text { Cell emigration } \\
- \text { control - }\end{array}$ & $\begin{array}{c}\text { Cell emigration } \\
- \text { U0126 - }\end{array}$ \\
\hline
\end{tabular}

\begin{tabular}{lcc}
\hline A172 & + & + \\
A1207 & + & - \\
C6 & + & - \\
SKMG-4 & + & + \\
SKMG-5 & + & - \\
SKMG-15 & - & - \\
TC620 & - & - \\
U87 & + & + \\
U178 & + & - \\
U251 & + & + \\
U373 & + & +
\end{tabular}

Glioma cells were treated as described in Table II and the borderline of circular monolayers inspected microscopically after a 72-h culture period $\pm 10 \mu \mathrm{M}$ U0126. + , presence of emigrated cells and presence of a ruffled borderline; -, absence of emigrated cells and presence of a smooth borderline.
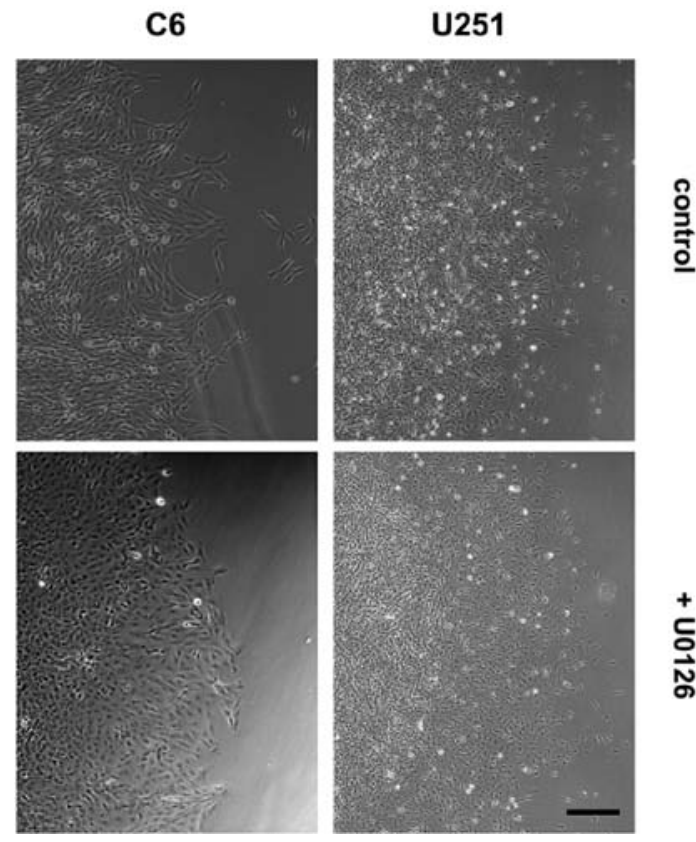

을

Figure 5. MEK/ERK1/2-dependent emigration of glial tumor cells from confluent monolayers. Circular confluent monolayers of C6 or U251 cells were cultured three days $\pm 10 \mu \mathrm{M}$ U0126 after what the monolayer's borderline was examined microscopically. Note the presence of a smooth borderline and the lack of single cells outside the monolayer for U0126-treated C6 cells. Bar, $200 \mu \mathrm{m}$.

Activated MEK/ERK1/2 promotes collective glioma cell migration. Glioma cells spotted onto Petri dishes formed a well-defined circular monolayer that allowed the analysis of collective cell migration (Fig. 3 for U373 cells). When integrated within a monolayer, all cells were capable to migrate on a plastic surface. With the exception of SKMG-15 and TC620 cells, a tendency of single cells to leave the cell collective was observed during the culture time, but still allowed a precise determination of the monolayer's diameter (Fig. 3, Table II). The increase in surface area occupied by cells (normalized per $\mathrm{mm}^{2}$ initial area) ranged from 0.22 (for SKMG-4 cells) up to $0.98 \mathrm{~mm}^{2}$ (for A172 cells); i.e. cells present on $1 \mathrm{~mm}^{2}$ can increase their surface per day to the maximum by another $1 \mathrm{~mm}^{2}$. In nine of eleven cell lines a significant reduction in the migration rate (ranging from 23 to 42\%) was observed upon U0126 treatment (Table II). Except for C6 cells, treatment with U0126 did not lead to disintegration of the actin cytoskeleton, as determined by TRITC-phalloidin staining (Fig. 4).

Activated MEK/ERK1/2 promotes single cell emigration. In the collective cell migration assay a considerable number of single cells was observed that had left the cell monolayer (except for SKMG-15 and TC-620 cells). In four cell lines emigration was completely abolished in the presence of U0126 (Fig. 5, Table III), suggesting that the MEK/ERK1/2 pathway can take part in controlling cell-to-cell adhesion.

Activated MEK/ERK1/2 promotes glioma-single cell migration. We further analyzed the migration pattern of single glioma cells. For this purpose, cells were cultured at low density with or without U0126 and the migration paths of individual cells were 

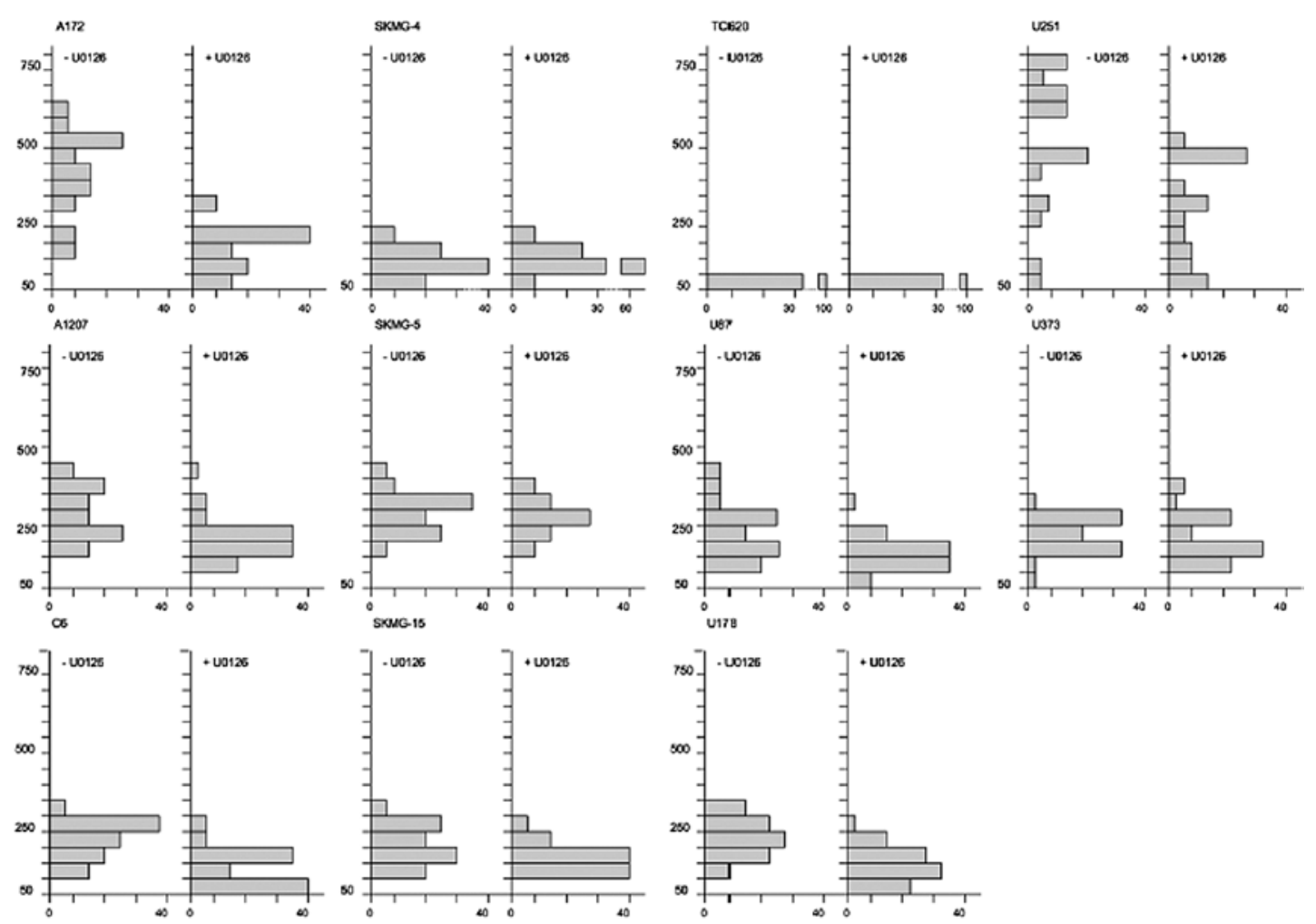

Figure 6. MEK/ERK1/2-dependent single cell migration of glioma cells. Twenty-four hour-lasting time laps analyses of glioma cells cultured at low density on plastic surfaces $\pm 10 \mu \mathrm{M}$ U0126 were performed. Subsequent tracing of migratory paths was accomplished with Image J software and on average 20 cells were analyzed per cell line and treatment. Graphs show total distances covered by individual cells. Distances plotted on the y-axis are split into $50 \mu \mathrm{m}$ bins and the number of glioma cells in each category (in percent) is given on the $\mathrm{x}$-axis.

Table IV. Impact of U0126 on single cell migration of glioma cells.

\begin{tabular}{|c|c|c|c|c|}
\hline Cell line & $\begin{array}{c}\text { Migration rate }(\mu \mathrm{m} / 24 \mathrm{~h}) \\
\text { - control - }\end{array}$ & $\begin{array}{c}\text { Migration rate }(\mu \mathrm{m} / 24 \mathrm{~h}) \\
-\mathrm{U} 0126-\end{array}$ & $\%$ inhibition & p-value \\
\hline A172 & $363 \pm 134$ & $143 \pm 73$ & 43 & $<0.001^{* * * *}$ \\
\hline A1207 & $242 \pm 80$ & $168 \pm 70$ & 30 & $<0.001^{* * *}$ \\
\hline C6 & $170 \pm 61$ & $87 \pm 60$ & 49 & $<0.001^{* * *}$ \\
\hline SKMG-4 & $84 \pm 35$ & $91 \pm 42$ & +8 & $<0.3$ \\
\hline SKMG-5 & $232 \pm 63$ & $210 \pm 85$ & 9 & $<0.2$ \\
\hline SKMG-15 & $160 \pm 58$ & $113 \pm 45$ & 30 & $<0.001^{* * *}$ \\
\hline TC620 & $23 \pm 9$ & $21 \pm 5$ & - & - \\
\hline U87 & $179 \pm 91$ & $113 \pm 56$ & 37 & $<0.001^{* * *}$ \\
\hline U178 & $186 \pm 64$ & $99 \pm 58$ & 52 & $<0.001^{* * *}$ \\
\hline $\mathrm{U} 251$ & $478 \pm 208$ & $260 \pm 147$ & 46 & $<0.001^{* * *}$ \\
\hline U373 & $178 \pm 73$ & $165 \pm 80$ & 7 & $<0.4$ \\
\hline
\end{tabular}

Glioma cells cultured at low density were treated $30 \mathrm{~h} \pm 10 \mu \mathrm{M} \mathrm{U} 0126$ and time-lapse analysis was performed during the final $24 \mathrm{~h}$ of treatment. Cell trajectories were evaluated with the Image J software for 20 cells per cell line and treatment. Mean values \pm SD are shown. Statistical significance was evaluated with the Wilcoxon two sample test. Asterisks indicate statistical significance.

recorded for $24 \mathrm{~h}$ (Fig. 6, Table IV). Amongst cell lines mean path lengths varied considerably; i.e. between 84 (SKMG-4 cells) and $478 \mu \mathrm{m}$ (U251 cells) per day. Remarkably, single TC620 cells did not migrate at all on a plastic surface. With the exception of SKMG-4, -5 and U373 cells, application of
U0126 led to a significant reduction in the migration rate by 30 (A1207) to 52\% (U178 cells).

Activated MEK/ERK1/2 is expressed in primary human stem cell-enriched glioma cells. We finally investigated the appear- 
A

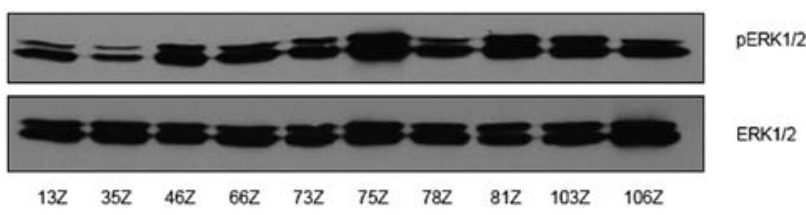

B

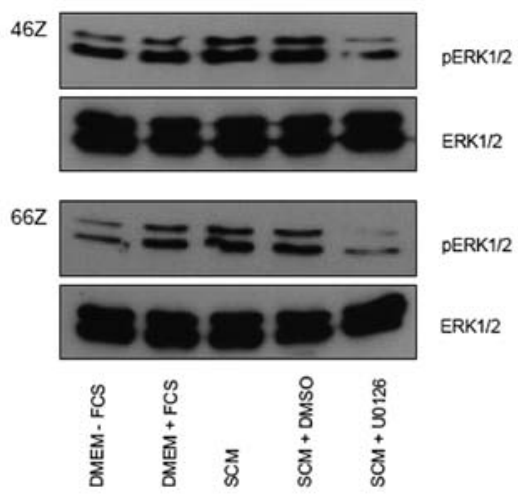

Figure 7. Western blot analysis of ERK1/2 activation in glioma stem cellenriched cultures. (A) Primary cultures of human glioblastoma cells were cultured in defined stem cell medium. (B) Primary cultures were maintained for $24 \mathrm{~h}$ in DMEM $\pm 10 \% \mathrm{FCS}$, or in stem cell medium (SCM) either in the absence of additives (SCM) or in the presence of DMSO or $10 \mu \mathrm{M}$ U0126. Cell lysates were analyzed for the presence of total or phosphorylated (p) ERK1/2 proteins using specific antibodies.

ance of pERK1/2 in stem cell-enriched primary cultures of patient-specific glioblastoma samples in a representative collection of previously characterized cells maintained under defined serum-free conditions (14). Activated ERK1/2 could be verified in all ten cultures tested (Fig. 7A). Moreover, the expression of pERK1/2 was not controlled by serum components and could be partially inhibited by U0126 treatment (Fig. 7B), suggesting the activation of MEK/ERK1/2-regulated signaling in glioma stem cells as well.

\section{Discussion}

In the present study we demonstrate that an aberrantly activated MAPK signal pathway is present in glioma (stem) cells that promotes proliferation, collective and single cell migration, as well as single cell emigration from monolayers.

Under normal culture conditions, the extent of ERK1/2 phosphorylation in most if not all glioma cells were incomplete since it could be hyperactivated by serum-stimulation of quiescent cells. Thus, the actual degree of activated ERK1/2 in glial tumor cells could be considerable higher. An extrapolation to the cellular level would imply that the proliferative and migratory potential of glioma cells is underestimated in our study.

The inhibition of ERK1/2 phosphorylation increased by U0126 treatment, but though almost complete (Fig. 1), it only led to a slowdown not to an entire arrest in cell proliferation and migration. Although this could be caused by a residual
pERK1/2 activity, it is more likely that multiple pathways are concomitantly involved in the control of such complex cell behavior. Paternot and Roger (14) have recently demonstrated that combined perturbation of MAPK/ERK1/2 and PI3/Akt/ mTOR signaling prevents proliferation of glioma cells more efficiently than inhibition of a single pathway. Moreover, PI3K pathway activation mediates resistance to MEK inhibitors in RAS mutant cancers (15).

In all glioma cells only a partial inhibition of proliferation was observed. Also on the single cell level, in preliminary Ki67-staining experiments we found no evidence for the appearance of a considerable number of resting cells upon U0126 treatment. The partial inhibition of cell cycle progression observed, could again reflect a cooperativity of different signaling pathways as demonstrated for MEK/ERK1/2 and PI3K/Akt pathways (16).

Greatly increased pERK1/2 levels do not per se lead to a greatly increased proliferation rate. Albeit we have not performed precise measurements, primary glioma stem cells used divided much slower than established glioma cell lines, although both express comparable amounts of pERK1/2. An explanation for such differences could be the presence of graded or switch-like ERK1/2-dependent response mechanisms (17). Treatment of quiescent 3 T3 cells with increasing concentrations of plateletderived growth factor induced a graded increase in ERK activity. However, only when ERK phosphorylation exceeded a certain threshold level, cells entered the $S$ phase and cell cycle progression was accompanied by a dramatic nuclear translocation of activated ERK (17).

During glial tumor development and progression also migratory processes play an essential role that means single as well as collective cell migratory events must be considered. Most of the glioma cells used in our study migrated as collective (11 out of 11) and as single cells (10 out of 11) on a plastic surface. Given more favorable conditions, i.e. a laminin substrate, also single TC-620 cells were capable of migration (not shown). Nevertheless, it is remarkable that collective TC-620 cells may constitute an environment that allows migration on unfavorable substrates, indicating that cell-cell interactions could partially substitute cell-substrate interactions. Histopathology of glioblastomas has revealed the presence of protruding fronts of collective tumor cells in motion, a finding supported by in silico histopathological models (18).

U0126 treatment abolishes collective and single cell migration. For a number of tumor cells such as breast cancer (19), pancreatic carcinoma (20) or fibrosarcoma cells (21), the contribution of the MEKERK1/2 module to promotion of cell migration has already been reported. Noteworthy, although elevated ERK1/2 activity correlates with an increased migratory potential, this is not necessarily coupled to an increased invasion potential in vitro, as shown for breast cancer cells (19). The migratory potential of glial tumor cells seems to increase their anti-apoptotic competence, as migrating glioma cells activate the PI3 kinase pathway and, thereby, are protected from camptothecin- and Trailinduced apoptosis (22). Therefore, an important question is whether the inhibition of MEK1/2/ERK1/2-regulated signaling pathways would also sensitize glioma cells for apoptotic stimuli. 
Another fatal feature of gliomas is the migration of solitary cells into native brain tissue, thus preventing the complete surgical resection of the primary tumor mass. The first step of this invasion process is the disintegration of individual cells from the tumor mass proper (23). The emigration of single tumor cells from a monolayer was observed in most cell lines may represent an in vitro 2D model of this process. The complete prevention of emigration by U0126 treatment suggests a strengthening of cell-cell interactions evoked by ERK1/2 inactivation.

The constitutive expression of pERK $1 / 2$ in primary glioma stem cell-enriched cultures is in line with data recently published (24). The authors have shown in a mouse model that activation of the Ras/MAPK pathway in combination with either Ink4a/Arf loss or Akt activation leads to the development of high-grade gliomas in vivo. Thus, it is likely that activation of the RAS/MAPK cascade is a key element in glioma initiation. In contrast, an in vivo model of human invasive U251 cells in the brain parenchyma of mice suggests a positive correlation of increased pERK $1 / 2$ expression with decreased stemness (25). Unfortunately, comparable data from primary tumors are currently not available.

In our study we have applied U0126 at a concentration that did not induce unspecific cell death. Although the responsiveness of different cell lines may vary, it is unlikely that a complete and specific cessation of cell migration and proliferation would have been obtained with higher drug concentrations. Transferred to clinical practice our data underline the need of combinatorial therapeutic strategies, all the more because the efficacy of small molecule kinase inhibitors in single drug glioblastoma therapies is to date disappointing and did not lead to a general benefit for patients (reviewed in refs. 26-28). This lack of efficacy could be caused by different limitations of the therapy regimes, mainly that: i) the inactivation of downstream targets was not analyzed, ii) the activity of the agent was restricted only to a subpopulation of patients, iii) single-agent therapy was ineffective due to the activity of alternative pathways, or iv) the study endpoints may not allow an evaluation of the benefit. To illustrate the state of the therapy with an (admittedly simplistic and theoretical) example: in our experiments U0126-provoked inhibition of cell proliferation, reduced the number of newly originated tumor cells on average by $92 \%$ after 10 divisions. These results from a difference in 3.6 cell divisions, i.e. the number of cells in control cultures after 10 divisions will be reached in U0126-treated cultures already 7 days later. During this time period, the total cell volume increases by factor of 12 . Within the broad time frame of clinical studies, such differences are not detectable (and would rightly not be judged as a benefit). The selective application of drugs at hand attacking the MEK/ ERK1/2 module is probably only promising for slowly dividing glial tumors. Thus, for more efficient strategies combination therapies are warranted that stop and not only partially inhibit tumor progression.

\section{Acknowledgements}

The authors thank Heike Höfer for excellent technical assistance and the Lichtenberg program of the VW Foundation for financial support (to B.S.).

\section{References}

1. Pearson G, Robinson F, Beers GT, Xu BE, Karandikar M, Berman K and Cobb MH: Mitogen-activated protein (MAP) kinase pathways: regulation and physiological functions. Endocr Rev 22: 153-183, 2001.

2. Sebolt-Leopold JS and Herrera R: Targeting the mitogen-activated protein kinase cascade to treat cancer. Nat Rev Cancer 4: 937-947, 2004.

3. Ebisuya M, Kondoh K and Nishida E: The duration, magnitude and compartmentalization of ERK MAP kinase activity: mechanisms for providing signaling specificity. J Cell Sci 118: 2997-3002, 2005.

4. Hoshino R, Chatani Y, Yamori T, et al: Constitutive activation of the 41-/43-kDa mitogen-activated protein kinase signaling pathway in human tumors. Oncogene 18: 813-822, 1999.

5. Towatari M, Iida $H$, Tanimoto $M$, Iwata $H$, Hamaguchi $M$ and Saito H: Constitutive activation of mitogen-activated protein kinase pathway in acute leukemia cells. Leukemia 11: 479-484, 1997.

6. Bhaskara VK, Panigrahi M, Challa S and Babu PP: Comparative status of activated ERK1/2 and PARP cleavage in human gliomas. Neuropathology 25: 48-53, 2005.

7. Mandell JW, Hussaini IM, Zecevic M, Weber MJ and Vandenberg SR: In situ visualization of intratumor growth factor signaling: immunohistochemical localization of activated ERK/ MAP kinase in glial neoplasms. Am J Pathol 153: 1411-1423, 1998.

8. Mawrin C, Diete S, Treuheit T, et al: Prognostic relevance of MAPK expression in glioblastoma multiforme. Int J Oncol 23: 641-648, 2003.

9. Pelloski CE, Lin E, Zhang L, et al: Prognostic associations of activated mitogen-activated protein kinase and Akt pathways in glioblastoma. Clin Cancer Res 12: 3935-3941, 2006.

10. Merlo A: Genes and pathways driving glioblastomas in humans and murine disease models. Neurosurg Rev 26: 145-158, 2003.

11. Kapoor GS and O'Rourke DM: Receptor tyrosine kinase signaling in gliomagenesis: pathobiology and therapeutic approaches. Cancer Biol Ther 2: 330-342, 2003.

12. Davies SP, Reddy H, Caivano M and Cohen P: Specificity and mechanism of action of some commonly used protein kinase inhibitors. Biochem J 351: 95-105, 2000.

13. Vladimirova V, Waha A, Luckerath K, Pesheva $\mathrm{P}$ and Probstmeier R: Runx 2 is expressed in human glioma cells and mediates the expression of galectin-3. J Neurosci Res 86: 2450-2461, 2008.

14. Glas M, Rath BH, Simon M, et al: Residual tumor cells are unique cellular targets in glioblastoma. Ann Neurol 68: 264-269, 2010.

15. Wee S, Jagani Z, Xiang KX, et al: PI3K pathway activation mediates resistance to MEK inhibitors in KRAS mutant cancers. Cancer Res 69: 4286-4293, 2009.

16. Mirza AM, Gysin S, Malek N, Nakayama K, Roberts JM and McMahon M: Cooperative regulation of the cell division cycle by the protein kinases RAF and AKT. Mol Cell Biol 24: 10868-10881, 2004.

17. MacKeigan JP, Murphy LO, Dimitri CA and Blenis J: Graded mitogen-activated protein kinase activity precedes switch-like c-Fos induction in mammalian cells. Mol Cell Biol 25: 4676-4682, 2005.

18. Frieboes HB, Lowengrub JS, Wise S, Zheng X, Macklin P, Bearer EL and Cristini V: Computer simulation of glioma growth and morphology. Neuroimage 37 (Suppl 1): S59-S70, 2007.

19. Krueger JS, Keshamouni VG, Atanaskova N and Reddy KB: Temporal and quantitative regulation of mitogen-activated protein kinase (MAPK) modulates cell motility and invasion. Oncogene 20: 4209-4218, 2001.

20. Klemke RL, Cai S, Giannini AL, Gallagher PJ, de Lanerolle P and Cheresh DA: Regulation of cell motility by mitogen-activated protein kinase. J Cell Biol 137: 481-492, 1997.

21. Webb DJ, Nguyen DH and Gonias SL: Extracellular signalregulated kinase functions in the urokinase receptor-dependent pathway by which neutralization of low density lipoprotein receptor-related protein promotes fibrosarcoma cell migration and matrigel invasion. J Cell Sci 113: 123-134, 2000.

22. Joy AM, Beaudry CE, Tran NL, Ponce FA, Holz DR, Demuth T and Berens ME: Migrating glioma cells activate the PI3-K pathway and display decreased susceptibility to apoptosis. J Cell Sci 116: 4409-4417, 2003. 
23. Sahai E: Mechanisms of cancer cell invasion. Curr Opin Genet Dev 15: 87-96, 2005.

24. Robinson JP, Vanbrocklin MW, Lastwika KJ, McKinney AJ, Brandner S and Holmen SL: Activated MEK cooperates with Ink4a/Arf loss or Akt activation to induce gliomas in vivo. Oncogene 30: 1341-1350, 2011.

25. Molina JR, Hayashi Y, Stephens C and Georgescu MM: Invasive glioblastoma cells acquire stemness and increased Akt activation. Neoplasia 12: 453-463, 2010.

26. De Witt Hamer PC: Small molecule kinase inhibitors in glioblastoma: a systematic review of clinical studies. Neuro Oncol 12: 304-316, 2010.
27. Mercer RW, Tyler MA, Ulasov IV and Lesniak MS: Targeted therapies for malignant glioma: progress and potential. BioDrugs 23: 25-35, 2009.

28. Thaker NG and Pollack IF: Molecularly targeted therapies for malignant glioma: rationale for combinatorial strategies. Expert Rev Neurother 9: 1815-1836, 2009.

29. Hecker D, Kappler J, Glassmann A, Schilling K and Alt W: Image analysis of time-lapse movies - a precision control guided approach to correct motion artefacts. J Neurosci Meth 172: 67-73, 2008. 